\title{
A MESSAGE FROM THE GOVERNOR-GENERAL
}

\author{
Government House, Ottawa
}

I send my greetings to the members of the Canadian Society of Forest Engineers, assembled in Montreal. The Forest Industries are among the most important in Canada, of which more than half the land area is covered by forests. One of the difficulties of your work is that it requires perhaps more imagination, more foresight and more patience than any other industry. I welcome the importance which is now attached to forestry, which is one of the most useful as well as one of the most healthful of human occupations. Directed as it is to checking reckless consumption of the supply of timber, and to teaching and encouraging thrifty use and prudent replacement, it represents a great work for the common good.

Our forests are a great national asset and it is for this reason in particular that the greatest care and attention should be paid by those in the vicinity to prevent damage of all kinds, especially by fire.

Your Society has made a valuable contribution to Canada's war effort. When the war is over, its work, skilfully directed and carefully applied, will have a direct bearing on Canada's economic future. 